\title{
Learning styles and teaching styles determine students' academic performances
}

\author{
Nithya Dewi Subramaniam Chetty ${ }^{1}$, Lina Handayani ${ }^{2}$, Noor Azida Sahabudin ${ }^{3}$, Zuraina $\mathrm{Ali}^{4}$, \\ Norhasyimah Hamzah ${ }^{5}$, Nur Shamsiah Abdul Rahman ${ }^{6}$, Shahreen Kasim ${ }^{7}$ \\ 1,3,6 Faculty of Computing, Universiti Malaysia Pahang, Malaysia \\ ${ }^{2}$ Faculty of Public Health, Universitas Ahmad Dahlan, Indonesia \\ ${ }^{4}$ Department of English, Centre for Modern Languages \& Human Sciences, Universiti Malaysia Pahang, Malaysia \\ ${ }^{5}$ Faculty of Technical and Vocational Education, Universiti Tun Hussein Onn Malaysia, Malaysia \\ ${ }^{7}$ Faculty of Computer Science \& Information Technology, Universiti Tun Hussein Onn Malaysia, Malaysia
}

\section{Article Info}

Article history:

Received Oct 2, 2019

Revised Nov 13, 2019

Accepted Nov 30, 2019

\section{Keywords:}

Academic performance

Learning style preference

Students

Teaching style preference

\begin{abstract}
Individuals learn in different ways using several learning styles, but lecturers may not always share material and learning experiences that match students' learning preferences. Mismatches between learning and teaching styles can lead to disappointment with students are taking, and lead to underperformance among them. The aim of this study is to identify the learning styles of the students enrolled in Universiti Malaysia Pahang who were registered in Programming Technique course and to investigate the relationship between students' learning styles and teachers' teaching styles. Five lecturers and 251 students were involved in the study as participants and. Data from students were collected using Leonard, Enid's VAK Learning Style Survey. Meanwhile, the teaching styles of the lecturers were identified using Grasha and Reichmann's Teaching Style Survey. The findings revealed that majority of the student's preferred visual learning style. The result also shows that the lecturers' teaching styles give an impact towards the students' academic performance. From this study, we can conclude that teaching styles have significant impacts on students' learning styles and academic performances.
\end{abstract}

Copyright $\odot 2019$ Institute of Advanced Engineering and Science. All rights reserved.

\section{Corresponding Author:}

Noor Azida Sahabudin,

Faculty of Computing,

Universiti Malaysia Pahang,

26600 Pekan, Pahang, Malaysia.

Email: azida@ump.edu.my

\section{INTRODUCTION}

Teaching and learning styles play a crucial role in this academic world. Diverse styles of teaching and learning occur due to the reaction among students in relation to the teaching styles that are demonstrated by the lecturers. This chain-reaction affects the students' learning styles preferences [1]. In addition, the diversity in teaching and learning styles preferences would result in matches and mismatches between the lecturers' teaching styles and students' learning styles.

According [2] learning style refers to students' preferred learning approaches for all learning situations while teaching styles refer to the lecturers' behavior, beliefs and selected instructional methods used to present lessons to students $[2,3,24]$. Currently, they are many research that are conducted on the concepts of students' learning style and educators' teaching style [4, 5].

In addition, students' learning styles reflect genetic coding, personality development, and environmental adaptations [6]. Research shows that students gain more knowledge, retain more information and perform better when the teachers' learning styles match with the students' learning styles [7]. However, 
According to Gilakjani, one of the weaknesses of the research in learning style is the lack of investigation concerning the matching of teaching and learning styles [8]. Due to this gap, the current study, therefore, aims at matching the students' learning styles and the lecturers' teaching styles. In other words, this study is conducted with the objective to examine the relationship between students' learning styles and lecturers' teaching styles. Also, the research evaluates the impact of teaching style toward students' academic performances.

\section{LITERATURE REVIEW}

In general psychology, the term learning styles refers to learners' favoured approach to learning, which includes the process of receiving, collecting, processing, and interpreting to become knowledgeable [9, $10,25]$. A general principle, educational and management approaches are considered as teaching style for a classroom instruction - how an educator imparts knowledge to their students [11].

Some researchers suggest that learning styles and teaching styles should be well matched in order to enhance students' motivation of learning $[12,13,26]$. Research done by [14] found that there was a positive relationship between self-efficacy and teachers teaching thinking practices whereas there was a negative relationship between personal model teaching style and teaching thinking skills. A different study conducted by [15] on the analysis of learning styles prevalent among secondary school students also tried to find the relationship and effect of different learning styles on academic achievements of students. Findings of the study revealed that, kinesthetic learning style was more prevalent than visual and auditory learning styles among secondary school students. Angela investigated a match or mismatch between learning and teaching styles in Science education among 179 students and 50 lecturers from Faculty of Science, Sana'a University, Yemen. According to the results, it showed that kinesthetic learning mode preference was reported as the major learning style among the students while visual and auditory learning style were as the minor learning styles demonstrated by them. Thus, the findings revealed that there is a mismatch between the learning style and teaching styles [16].

Meanwhile, a study conducted by [17] was find out the impact of teaching and learning style preferences and their match/mismatch on learners' achievement among 310 English Major Students and four (4) lecturers from the Foreign Languages Faculty of Azad University, Iran. The results of the study revealed that matching teaching and learning styles in EFL classes helped to improve students' achievement [17].

A study conducted by [18] was examine the effect of the match between the Learning and Teaching Styles of Teachers on Students' Achievement among 700 students and 31 teachers. The results of this study revealed that teachers created the learning surroundings depending on their own learning styles and that there has been a close relationship between teachers' learning styles, students' learning styles and students' achievements in mathematics classes, that students' achievements increased when teaching is done based on their learning styles. Besides that, the study revealed that there was a significant relationship between teachers' teaching style and students' learning style and students' academic achievements if they match with one another learning style [18]. The result obtained with this study has parallelism with those of some other studies in the literature [19-21].

Having to discuss studies concerning learning styles and teaching styles, it is evident that the issue of matching teaching styles and learning styles is controversial and the topic needs for more thorough research. It can be concluded that an effective teacher needs to have a resource bank of different teaching methods and activities to draw on from time to time so that maximum can be facilitated [22].

\section{METHOD}

The quantitative research approach includes the collection and analysis of numerical data to describe and generalize conditions, investigate relationships, and study the cause-effect of phenomena. The sample for this study was 251 undergraduates' students from Faculty of Computing, UMP who have taken the Programming Techniques subject and five lecturers.

To investigate the learning styles of the students, questionnaires were distributed to the students via online (Google Forms). The questionnaire was constructed based on VAK Learning Styles Questionnaire (LSQ); adopted from Leonard, Enid. College Success Simplified, 2005. It consists of three styles assessed by 30 items, 10 items for each style. Each item requires the student to answer Yes or No. The highest score indicates the students' preference. The lowest score indicates weakest modality. If all three scores are identical, the students have truly integrated all three modalities and can work equally well in any of the modalities.

The Teaching Style Survey (TSS) by Grasha-Riechmann is an instruments that was employed in this study. TSS questionnaire contains 40 questions in five sections that include the questions of Expert method 
(8 items), Formal authority (8 items), Personal model (8 items), Facilitator (8 items) and Delegator (8 items). Likert scales statements are used to range students' preferences of an item in the questionnaire in that the scales range from completely agree to completely disagree. The questions have ranked from 1 (extremely disagree) to 5 (extremely agree). The total score of each segment was partitioned to 8 as per the questionnaire index in each teaching method.

The main data sources of the proposed study are from questionnaire results and from students' academic performance. The questionnaire data was analyzed quantitatively. Statistical Package for the Social Sciences (SPSS) Version 17.0 was used to analyze students' responses towards the learning style preferences questionnaire and teachers' responses towards the teaching style preference questionnaire. In this study, there are two type of datum which are called nominal data and ordinal data. A profile of results was established for each participant. The frequency distribution of questionnaire results was examined. The means for each item were calculated and items with higher use were identified. The standard of $p<.05$ was used to determine the statistical significance of results.

\section{RESULT AND DISCUSSION}

The respondents were asked to answer the questions listed in VAK LSQ. The three (3) learning styles were tested in VAK LSQ include: Visual (V), Auditory (A) and Kinaesthetic (K). Highest score in a given dimension would mean that the student prefers that particular learning style. Further, in this study, the students'learning style preferences reported include: unimodal (one strong dimension), bimodal (two strong dimensions) and trimodal/multimodal (three strong dimensions).

The Figure 1 shows that the most preferred learning style by the students is the unimodal dimension with $49.8 \%$ which involve only the visual style. In other words, majority of the students have strong visual modality. The Visual learning style is followed by the Kinaesthetic Style (unimodal) with 40 (15.94\%) of the respondents and on third position is the bimodal dimension Visual and Kinaesthetic (V/K) with $11.95 \%$ of the respondents reporting their preference on it. The least preferred learning style dimensions are the trimodal VAK dimension and bimodal Auditory/Kinesthetic (A/K) dimension which had $3.98 \%$ and $4.38 \%$ preference levels respectively.

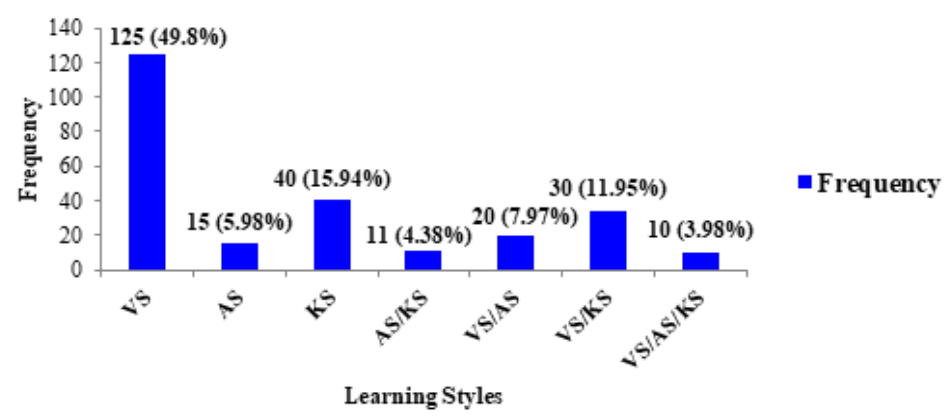

Figure 1. Students' learning style preference

Table 1 shows that the most preferred teaching style by the lecturer is the Facilitator which involve guides and directs students by asking questions, exploring options, suggesting alternatives, and encouraging them to develop criteria to make informed choices. The rest demonstrated Delegator, Formal Authority and Personal Model teaching styles where $20 \%$ each style.

Table 1. Lecturers' teaching style preferences

\begin{tabular}{lcc}
\hline \multicolumn{1}{c}{ Teaching style } & Frequency & Percentage \\
\hline Expert & 0 & $0 \%$ \\
Formal Authority & 1 & $20 \%$ \\
Personal Model & 1 & $20 \%$ \\
Facilitator & 2 & $40 \%$ \\
Delegator & 1 & $20 \%$ \\
\hline
\end{tabular}


To identify students learning styles and lecturers' teaching styles, descriptive analysis technique was used. The teaching style i.e. Grasha-Riechmann Teaching Style Inventory was employed to Programming Technique lecturers. Each section was conducted by 1 lecturer. Section means class that is conducted by the lecturers. Table 2 reveals the teaching style of the lecturer according to the section they are teaching. Lecturers section 2 and 3 shares same technique of teaching style whereas the rest are different.

Table 2. Lecturers' teaching style according to the section

\begin{tabular}{cc}
\hline Section & Teaching style \\
\hline 1 & Formal Authority \\
2 & Facilitator \\
3 & Facilitator \\
4 & Delegator \\
5 & Personal Model \\
\hline
\end{tabular}

The Figure 2 describes the learning styles of students who involve in this study acording to their class section. Visual style is the most preferred learning style in every sections. Section 2 has the higher number of students compare to other sections.

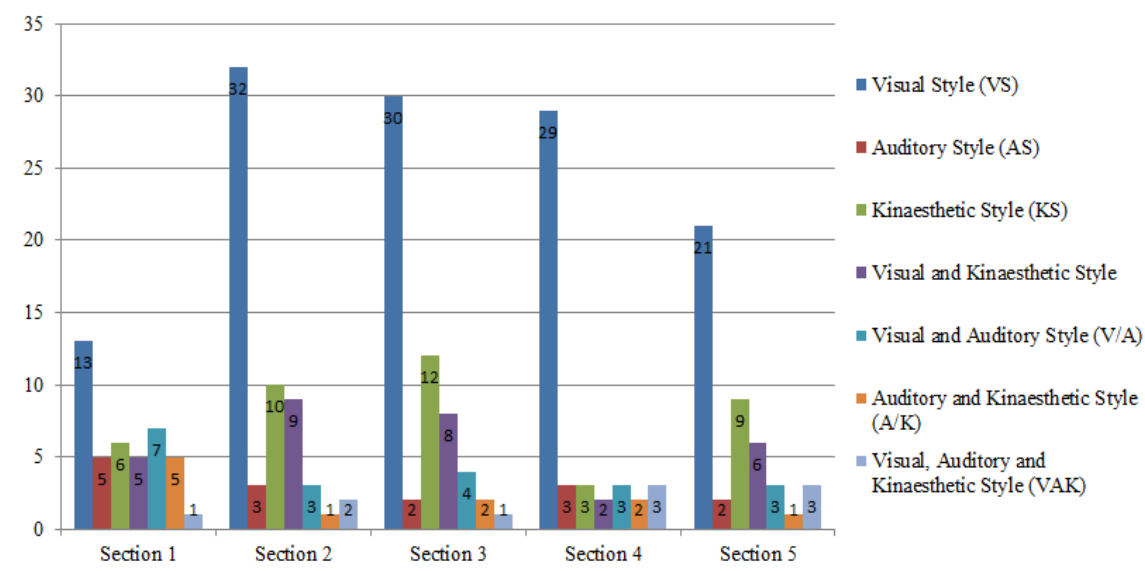

Figure 2. Number of students in each section

To evaluate the impact of teaching style and learning style towards students' academic performance, Table 3 shows final status of students in Programming Technique, whether they manage to pass or fail in their final exam. Unimodal learners and multimodal learners have positive and strong relationship on every teaching style. This would be considered as a matched teaching and learning styles. On the other hand, bimodal learning styles mismatched with certain teaching style. There is a mismatch between facilitator teaching style and visual and kinaesthetic style (V/K), visual and auditory style (V/A) and auditory and kinaesthetic style $(\mathrm{A} / \mathrm{K})$ learning styles. $55 \%$ of bimodal learners are not doing well in this class. Besides that, personal model and formal authority teaching style are matching with all the learning styles except visual and auditory style (V/A) learning style. Majority of the visual and auditory style (V/A) learners in this classes are not doing well in their exam. So, there was mismatch between visual and auditory style (V/A) and Formal Authority and Personal Model teaching style. When examined the Delegator teaching style, the relationships for the bimodal learning styles was moderate level. For instance, the relationship between the Visual and Kinaesthetic Style (V/K) learning style and Delegator teaching style was balance and relationship between auditory and kinaesthetic style $(\mathrm{A} / \mathrm{K})$ learning style was negative. Table 4 shows the summary of the result from the Table 3.

The results show that there is an impact on academic performance among students and lecturers if there is a mismatch occurred between the learning style and teaching style [24]. It was observed that most of the lecturers did not use a multiple of teaching method to match the learning style preference of each student. Instead, most of them employed only a single style of teaching. As a result, there was a mismatch between the students' learning style preferences and the teachers' instructional approach which may highly influence students' attitudes and motivation. For future research it is recommended that the researchers use a huge 
sample in order to obtain more reliable, informative and better results. This is because present study was restricted to only Programming technique students and lecturers which did not involve all other subject lecturers and students. The researcher agrees with Peacocks' suggestions that the lecturers and teaching materials and syllabuses always have to include assortment of learning and teaching styles [23].

Table 3. Student's academic performance verses lecturers' teaching style

\begin{tabular}{|c|c|c|c|c|c|c|c|}
\hline \multicolumn{8}{|c|}{ Teaching style: Facilitator } \\
\hline Grade & VS & AS & $\mathrm{KS}$ & $\mathrm{V} / \mathrm{K}$ & V/A & $\mathrm{A} / \mathrm{K}$ & VAK \\
\hline Pass & 39 & 5 & 19 & 8 & 3 & 1 & 3 \\
\hline Failed & 23 & 0 & 3 & 9 & 4 & 2 & 0 \\
\hline Relationship & Positive & Positive & Positive & Negative & Negative & Negative & Positive \\
\hline \multicolumn{8}{|c|}{ Teaching style: Personal Model } \\
\hline Grade & VS & AS & $\mathrm{KS}$ & $\mathrm{V} / \mathrm{K}$ & V/A & $\mathrm{A} / \mathrm{K}$ & VAK \\
\hline Pass & 20 & 2 & 9 & 5 & 1 & 1 & 3 \\
\hline Failed & 1 & 0 & 0 & 1 & 2 & 0 & 0 \\
\hline Relationship & Positive & Positive & Positive & Positive & Negative & Positive & Positive \\
\hline \multicolumn{8}{|c|}{ Teaching style: Delegator } \\
\hline Grade & VS & AS & $\mathrm{KS}$ & $\mathrm{V} / \mathrm{K}$ & V/A & $\mathrm{A} / \mathrm{K}$ & VAK \\
\hline Pass & 24 & 3 & 2 & 1 & 2 & 0 & 2 \\
\hline Failed & 5 & 0 & 1 & 1 & 1 & 2 & 1 \\
\hline Relationship & Positive & Positive & Positive & Balance & Positive & Negative & Positive \\
\hline \multicolumn{8}{|c|}{ Teaching style: Formal Authority } \\
\hline Grade & VS & AS & $\mathrm{KS}$ & $\mathrm{V} / \mathrm{K}$ & V/A & $\mathrm{A} / \mathrm{K}$ & VAK \\
\hline Pass & 8 & 4 & 5 & 4 & 3 & 5 & 1 \\
\hline Failed & 5 & 1 & 1 & 1 & 4 & 0 & 0 \\
\hline Relationship & Positive & Positive & Positive & Negative & Negative & Negative & Positive \\
\hline
\end{tabular}

Table 4. Relationship between Teaching style and Learning style

\begin{tabular}{ll}
\hline Learning Style & Relationship - Teaching style \\
\hline Visual Style (VS) & Match - all \\
Auditory Style (AS) & Match - all \\
Kinaesthetic Style (KS) & Match - all \\
Visual and Kinaesthetic Style & Match - Personal Model and Formal Authority \\
$(\mathrm{V} / \mathrm{K})$ & Mismatch - Facilitator \\
& Balance - Delegator \\
Visual and Auditory Style (V/A) & Match - Delegator \\
& Mismatch - Facilitator, Personal Model and Formal Authority \\
Auditory and Kinaesthetic Style (A/K) & Match - Personal Model and Formal Authority \\
& Mismatch - Facilitator and Delegator \\
Visual, Auditory and Kinaesthetic Style (VAK) & Match - all \\
\hline
\end{tabular}

\section{CONCLUSION}

Based on the analysis, the study showed that most respondents i.e. students, preferred and mainly demonstrated visual learning styles, followed by Kinaesthetic style (KS), Visual and Kinaesthetic style(VK), Visual and Auditory style (VA), Auditory and Kinaesthetic style (AK), Visual Auditory and Kinaesthetic style (VAK) and Auditory style(AS). Students with visual and kinaesthetic learning styles show good achievement, while some student with bimodal learning styles do not achieve good results. The study found a significant relationship between learning styles and teaching styles because it can increase or decrease students' academic performances. Therefore, lecturers need to prepare a few types of material on a same topic and conduct their classes in various ways to ensure that they may assist student to understand what the lecturers are trying to deliver in their learning way.

\section{ACKNOWLEDGEMENTS}

This research is supported by UMP Research Grant Scheme, RDU1703270. The authors fully acknowledged Universiti Malaysia Pahang (UMP) for the approved fund which makes this important research viable and effective.

\section{REFERENCES}

[1] D. M. Jepsen, M. M. Varhegyi, and S. T. T. Teo, "The association between learning styles and perception of teaching quality," Educ. and Train., vol. 57(5), pp. 575-587, Jul 2015. 
[2] L. Mei Ph'ng, "Teaching Styles, Learning Styles and the ESP Classroom," MATEC Web Conf., vol. 150, pp. 5082, 2018.

[3] L. M. Ph'ng, T. S. Ming, and R. M. K. Nambiar, "Match or mismatch: Teaching styles and learning styles in an ESP classroom," Soc. Sci., vol. 11(12), pp. 2977-2982, 2016.

[4] J. Cuevas, "Is learning styles-based instruction effective? A comprehensive analysis of recent research on learning styles," Theory Res. Educ., vol. 13, 2015.

[5] Y. Li, J. Medwell, D. Wray, L. Wang, and L. Xiaojing, "Learning styles: A review of validity and usefulness," $J$. Educ. Train. Stud., vol. 4(10), pp. 90-94, 2016.

[6] C. S. Guy and S. Denson-Guy, "An Introduction to Learning and Teaching Styles: Making the Match," Fisheries, vol. 20:2(2), pp. 18-20, Feb 2011.

[7] S. A. Husin, "Matching teaching styles with students'learning styles (A survey of Indonesian students'habits of learning)," Let Linguist. Lit. English Teach. J., vol. 6(2), 2017.

[8] A. P. Gilakjani, "A match or mismatch between learning styles of the learners and teaching styles of the teachers," Int. J. Mod. Educ. Comput. Sci., vol. 4, pp. 51, 2013.

[9] D. A. Kolb, "Experiential learning: Experience as the source of learning and development," FT press, 2014.

[10] W. L. H. Wong, "A study of language learning style and teaching style preferences of Hong Kong community college students and teachers in English for Academic Purposes (EAP) Contexts," 2015.

[11] M. Alami and P. Ivaturi, "Typical teaching styles among ELC Lecturers at Salalah College of technology," Oman, vol. 3, 2016.

[12] B. J. Ghaedi, Zahra, "Relationship between learning styles and motivation for higher education in EFL students," Theory Pract. Lang. Stud., vol. 4(6), 2014.

[13] B. M. Yassin and Mohammad Abdulmajid Almasri, "How to accommodate different learning styles in the same classroom: Analysis of theories and methods of learning styles," Can. Soc. Sci., vol. 11(3), pp. 26-33, 2015.

[14] Y. Dilekli and E. Tezci, "The relationship among teachers' classroom practices for teaching thinking skills, teachers' self-efficacy towards teaching thinking skills and teachers' teaching styles," Think. Ski. Creat., vol. 21, 2016.

[15] R. Vaishnav, "Learning style and academic achievement of secondary school students," Mar. 2013.

[16] R. M. Abu-Asba, Angela, Hazita Azman, "A match or mismatch between learning and teaching styles in science education," Int. J. Educ. Res., vol. 2(3), 2014.

[17] Z. Naimie, S. Siraj, C. Y. Piaw, R. Shagholi, and R. A. Abuzaid, "Do you think your match is made in heaven? Teaching styles/learning styles match and mismatch revisited," Procedia-Soc. Behav. Sci., vol. 2(2), pp. 349$353,2010$.

[18] F. T. D. Övez and S. M. Uyangör, "The effect of the match between the learning and teaching styles of secondary school mathematics teachers on students' achievement," J. Educ. Pract., vol. 7(29), pp. 125-132, 2016.

[19] S. Dinçol, S. Temel, Ö. Ö. Oskay, Ü. I. Erdolugan, and A. Ylilmaz, "The effect of matching learning styles with teaching styles on success," Procedia-Social Behav. Sci., vol. 15, pp. 854-858, 2011.

[20] N. Ford and S. Y. Chen, "Matching/mismatching revisited: An empirical study of learning and teaching styles," Br. J. Educ. Technol., vol. 32(1), pp. 5-22, 2001.

[21] P. Di Muro and M. Terry, "A matter of style: Applying Kolb's learning style model to college mathematics teaching practices," J. Coll. Read. Learn., vol. 38(1), pp. 53-60, 2007.

[22] T. E. Dorgu, "Different teaching methods: A panacea for effective curriculum implementation in the classroom," Int. J. Second. Educ., vol. 3(6), pp. 77-87, 2015.

[23] M. Peacock, "Match or mismatch? Learning styles and teaching styles in EFL.," Int. J. Appl. Linguist., vol. 11, 2001.

[24] A. F. Baharudin, N. A. Sahabudin and A. Kamaludin, "Behavioral Tracking in E-Learning by Using Learning Styles Approach," Indonesian Journal of Electrical Engineering and Computer Science., vol. 8 (1), pp. 17-26, 2017.

[25] N. A. Sahabudin and M. B. Ali, "Personalized learning and learning style among upper secondary school students, " Procedia-social and behavioral sciences., vol. 103, pp. 710-716.

[26] N. S. A. Rahman, M. S. Othman and W. Al-Rahmi, "Exploring the use of social media tools among students for teaching and learning," Journal of Theoretical and Applied Information Technology., vol. 91(1), pp.49-59, 2016. 